\title{
A New Strategy for the Treatment of Atherothrombosis - Inhibition of Inflammation
}

\author{
J. SLÍVA ${ }^{1}$, C. CHARALAMBOUS ${ }^{1}$, J. BULTAS ${ }^{1}$, D. KARETOVÁ ${ }^{2}$ \\ ${ }^{1}$ Department of Pharmacology, Third Faculty of Medicine, Charles University, Prague, Czech \\ Republic, ${ }^{2}$ Second Department of Medicine - Department of Cardiovascular Medicine, First \\ Faculty of Medicine, Charles University and General University Hospital in Prague, Prague, Czech \\ Republic
}

Received August 30, 2019

Accepted September 8, 2019

\begin{abstract}
Summary
Improvement in the prognosis of patients at risk of atherothrombotic events is based on three pillars - slowing down the process of atherogenesis (i.e. the development of atherosclerotic plaque), stabilizing the current atherosclerotic plaque, and reducing the risk of thrombotic occlusion in cases with unstable atherosclerotic plaque. The current prophylaxis has so far taken into consideration the adjustment of several risk factors, including dyslipidemia, arterial hypertension, smoking, and diabetes through lifestyle changes or pharmacological therapies. An essential part of prophylaxis is the anti-thrombotic strategy, especially anti-platelet therapy. Recently, a new pathway has been developed, based on reducing the activity of the inflammatory process with NLRP3 inflammasome, specifically a monoclonal antibody against interleukin $1 \beta$ (canakinumab). The efficacy and safety of this treatment, in secondary prevention, were documented in the CANTOS study. Other therapeutic procedures, including suppression of the inflammatory component of atherogenesis, are at the stage of clinical assessment.
\end{abstract}

\section{Key words}

Atherothrombosis • C-reactive protein - Anti-inflammatory therapy

- Canakinumab • Interleukin $1 \beta$

\section{Corresponding author}

J. Bultas, Department of Pharmacology, Third Faculty of Medicine, Charles University, Ruska 87, Prague 10, 100 34, Czech Republic. E-mail: jan.bultas@lf3.cuni.cz

\section{Introduction}

Atherosclerosis and its complications (atherothrombotic events) are perceived by a vast majority of the population as diseases of affluence. They are usually managed, or their onset can be significantly delayed through lifestyle modifications. However, atherosclerosis is not a disease of affluence; it was a common disease 3-4 thousand years ago. According to the HORUS study, the examination of more than fifty Egyptian mummies showed advanced atherosclerotic changes in the carotid and coronary region of the arterial supply of the limbs. In these areas, changes were present almost half of the individuals who died between 30 and 50 years of age (Allam et al. 2014). Thus, it is safe to say that atherosclerosis is rooted deep in our past, and it is unlikely that atherothrombotic diseases will be eradicated in the near future with nothing more than a "healthier" lifestyle. That it is why, at the forefront of our interest, we seek effective and safe treatment through improved prophylaxis. In addition to the well-established strategies, such as risk factors and antithrombotic therapy, a new tactic based on these three-pillars is being approached: suppression of 1) the inflammatory component of atherogenesis, 2) the inflammatory components leading to plaque destabilization, and 3) the inflammatory component of hemostasis, where the thrombus causes arterial occlusion. 
What is the importance of inflammatory/ reparative response in the atherothrombotic process?

Atherogenesis is a complex process of chronic inflammatory and reparative responses affecting the vessel wall. Initially, activation of endothelial cells occurs with the development of endothelial dysfunction caused by a series of NOx responses. Other factors include atherogenic dyslipidemia (particularly increased plasma concentrations of low-density lipoprotein (LDL), with mostly small dense particles (sdLDL)), tobacco smoke damage, the effects of high blood pressure, certain metabolic imbalances associated with diabetes and hyperglycemia, and the action of hyperactivated regulatory mechanisms linked to hypertension, diabetes, or other metabolic diseases. Endothelial dysfunction and the presence of atherogenic lipids allow the accumulation of cholesterol in the subendothelial space and further modification (oxidation, glycation, or nitrosylation). Subsequently, the expression of vasoadhesive molecules allows the migration of monocytes into the subendothelial spaces and their conversion to phagocytic macrophages, in this case, phagocytizing molecules of cholesterol. Physiologically, the macrophage enters the circulation, where it transfers cholesterol to high-density lipoproteins (HDL). At a higher concentration of oxidized or otherwise modified cholesterol, the macrophage loses its ability to move and remains in situ as a foam cell. This cell undergoes necrosis, releases the contents into the subendothelial layer and becomes the base of the core plaque (extracellular matrix deposition). If the plaque is already developed, the macrophage contributes to its destabilization through the production of metalloproteases (elastases, collagenases, etc.). In addition to monocytes/ macrophages, other components of the vascular wall, particularly proliferating smooth muscle cells, are involved in atherogenesis. From a clinical point of view, the riskiest period is when exposed collagen fibers activate primary (platelet) hemostasis, which may lead to an atherothrombotic event. However, most plaques do not undergo destabilization, and even most of the destabilized plaques are not accompanied by occlusion of the artery.

Inflammation, mostly inflammatory/reparative responses, is involved in the process of atherothrombosis in several stages (Figs 1, 2 and 3). Endothelial cells are activated by cytokines, like tumor necrosis factor $\alpha$ $(\mathrm{TNF} \alpha)$ or interleukins 1 and 4 ; even at the early stage of the process, the penetration of atherogenic lipoproteins is apparent. Vasoadhesive molecules (E-selectin or vascular cell adhesion molecule 1 (VCAM-1) produced by activated endothelial cells, mediate infiltration of the vascular wall by monocytes/macrophages. During the process of differentiation of monocytes into macrophages, colony-stimulating factor (M-CSF) (Fig. 1a) plays an important role. The actual inflammatory component, i.e. the infiltration of the vascular wall by macrophages, is essentially reparative. It leads to the removal of accumulated cholesterol and its esters from the subendothelial layer. However, the problem occurs when monocytes do not return to the circulation and remain in situ in the vessel wall. This is the case, for example, with higher concentrations of oxidized, acetylated, glycosylated, or otherwise modified cholesterol, which is phagocytized, in particular, by type A scavenger receptors (SR-A). Such macrophages, filled with lipids, are unable to travel and remain as foam cells. In large concentrations, they become the nucleus of atherosclerotic plaque.

Therapeutically, this phase is particularly affected by decreasing the concentration of atherogenic and thrombogenic lipoproteins, especially LDL and sdLDL or lipoprotein (a) (Lp(a)). We intervened with dietary measures, hypolipidemics, or specific techniques (e.g. plasmapheresis). The activation of endothelial cells and excessive infiltration of the monocyte/macrophage vessel wall was influenced by the managing other risk factors (especially smoking, hypertension, and diabetes); the blockade of vasoadhesive molecules was also tested, and, as shown below, anti-inflammatory therapy was also effective (Fig. 1b).

Pathological conditions in the vessel wall, such as high oxidative stress, high glucose levels, etc., lead to cholesterol modification, foam cell development, and development of the lipid core of the plaque. At this stage, the inflammatory-reparative process is already involved with the above-mentioned infiltration of the vascular wall by lipoprotein and monocytes/macrophages (Fig. 2a). Therapeutically, we can intervene at this level primarily by reducing the supply of atherogenic lipoproteins and preventing their modification. There is no conclusive evidence of the effects of reducing oxidative stress, but probably well-controlled glycemia in diabetics contributes to the slowing of microvascular diabetic complications (Fig. 2b). At the assessment stage, there are different vaccination strategies, e.g. against modified LDL. Promising preclinical tests have been published with antibodies against oxidized LDL or against apolipoprotein B (Kimura et al. 2015). Similarly, the stabilizing effect of metalloprotease inhibitors on the plaque is being examined. 


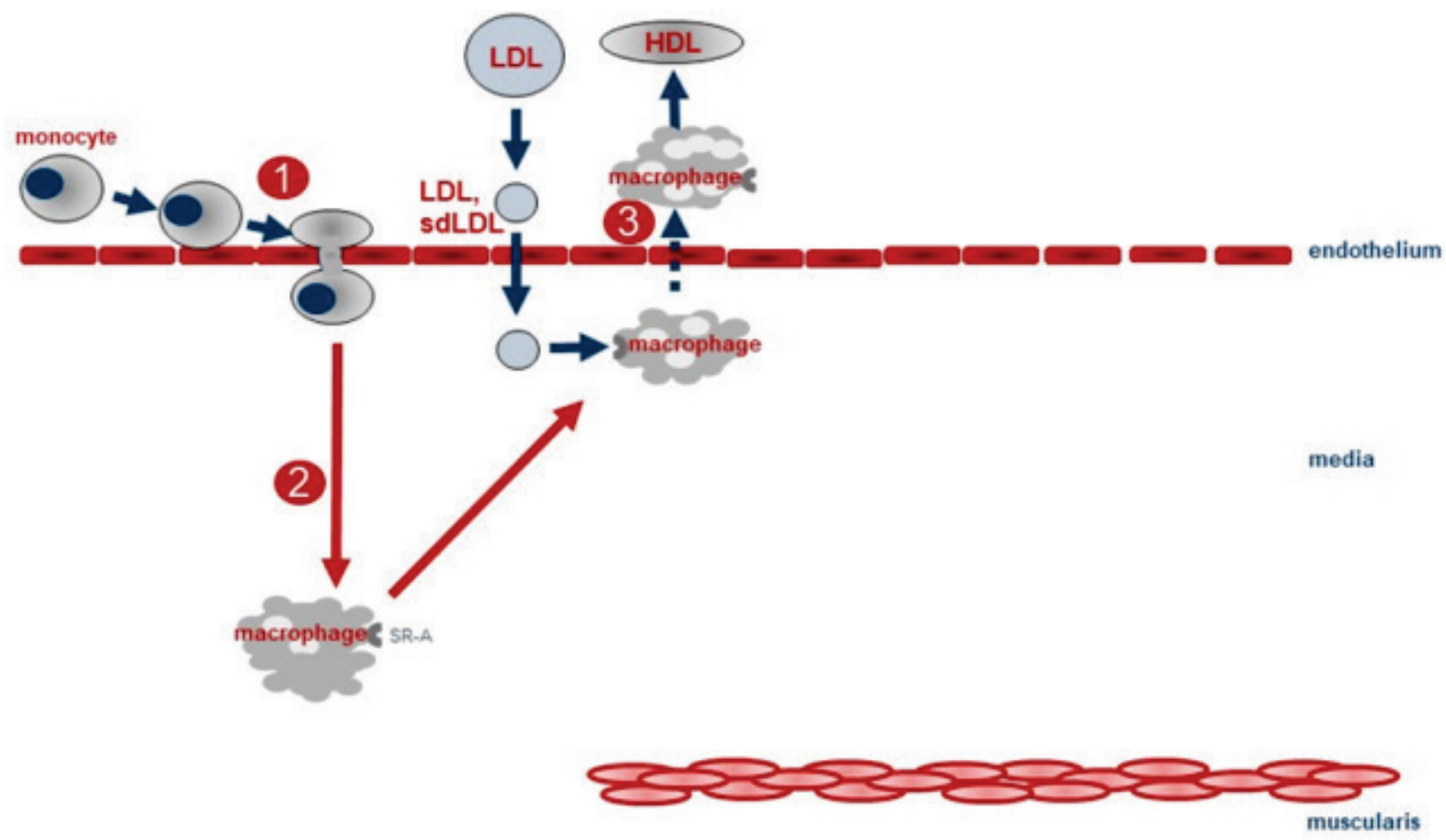

Fig. 1a. Lipid infiltration of the subendothelial space. Endothelial dysfunction and high concentrations of atherogenic lipoproteins (LDL lipoprotein) and especially small dense low-density lipoprotein (sdLDL) lead to the infiltration of the subendothelial space, in particular, by cholesterol and cholesterol esters. Purification of the subendothelial space from extracellularly stored cholesterol is ensured by phagocytic monocytes/ macrophages associated with scavenger receptor type A (SR-A). Subsequently the macrophages, after leaving, can transfer phagocytized cholesterol to lipoprotein type HDL. This phase is reversible.

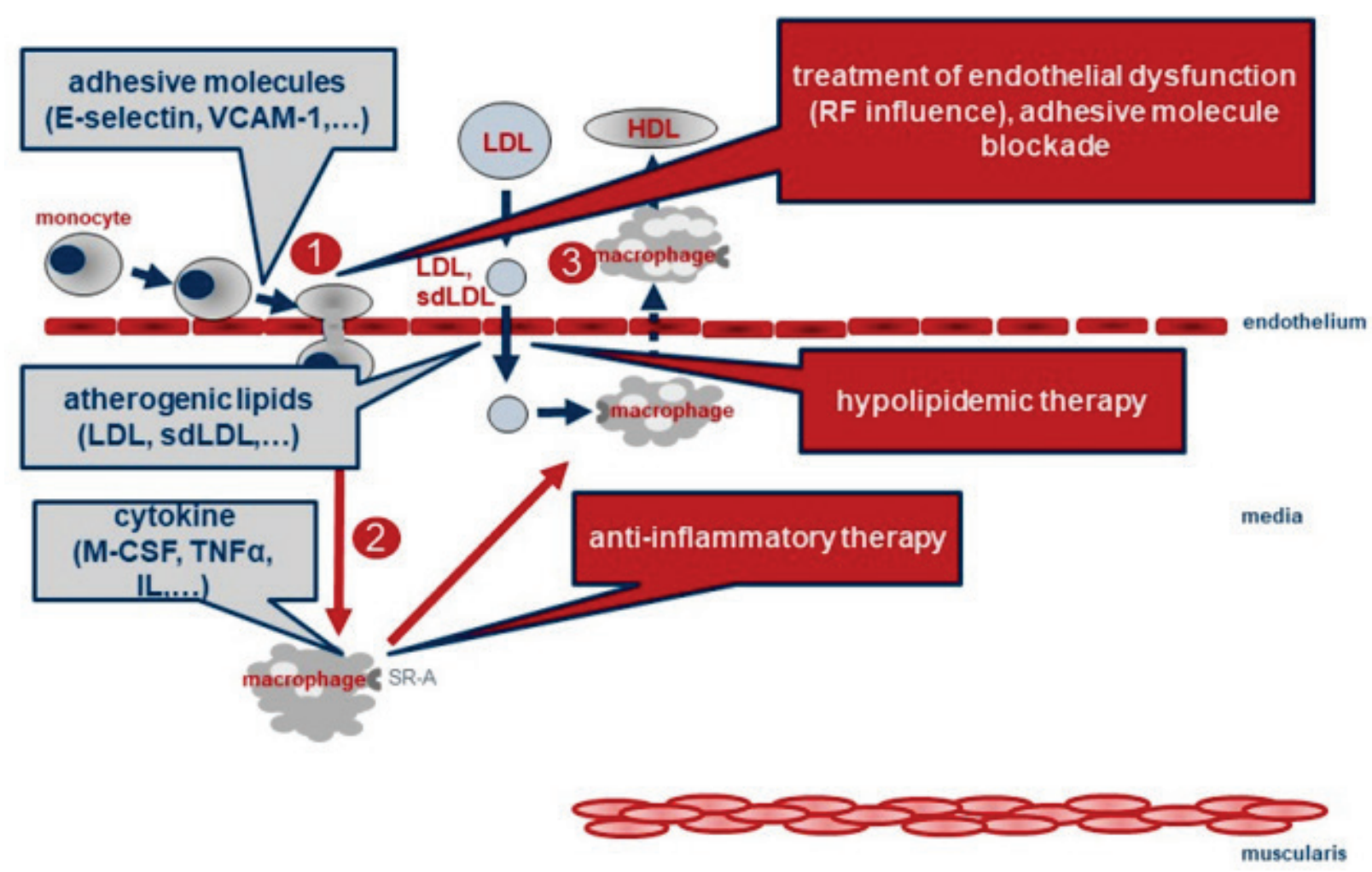

Fig. 1b. Participation of inflammatory components and the potential for therapeutic intervention during the phase of lipid infiltration of the subendothelial space. In addition to the atherogenic lipoproteins, vasoadhesion molecules, e.g. vascular cell adhesion molecule 1 (VCAM-1), facilitate the infiltration of subendothelial monocytes/macrophages. The process itself is significantly activated by specific cytokines, e.g. macrophage differentiation is activated by macrophage colony-stimulating factor (M-CSF). Hence, the goal was to intervened at the level of (1) blockade of vasoadhesive molecules, (2) targeted or non-specific anti-inflammatory treatments, and (3) risk factors. 


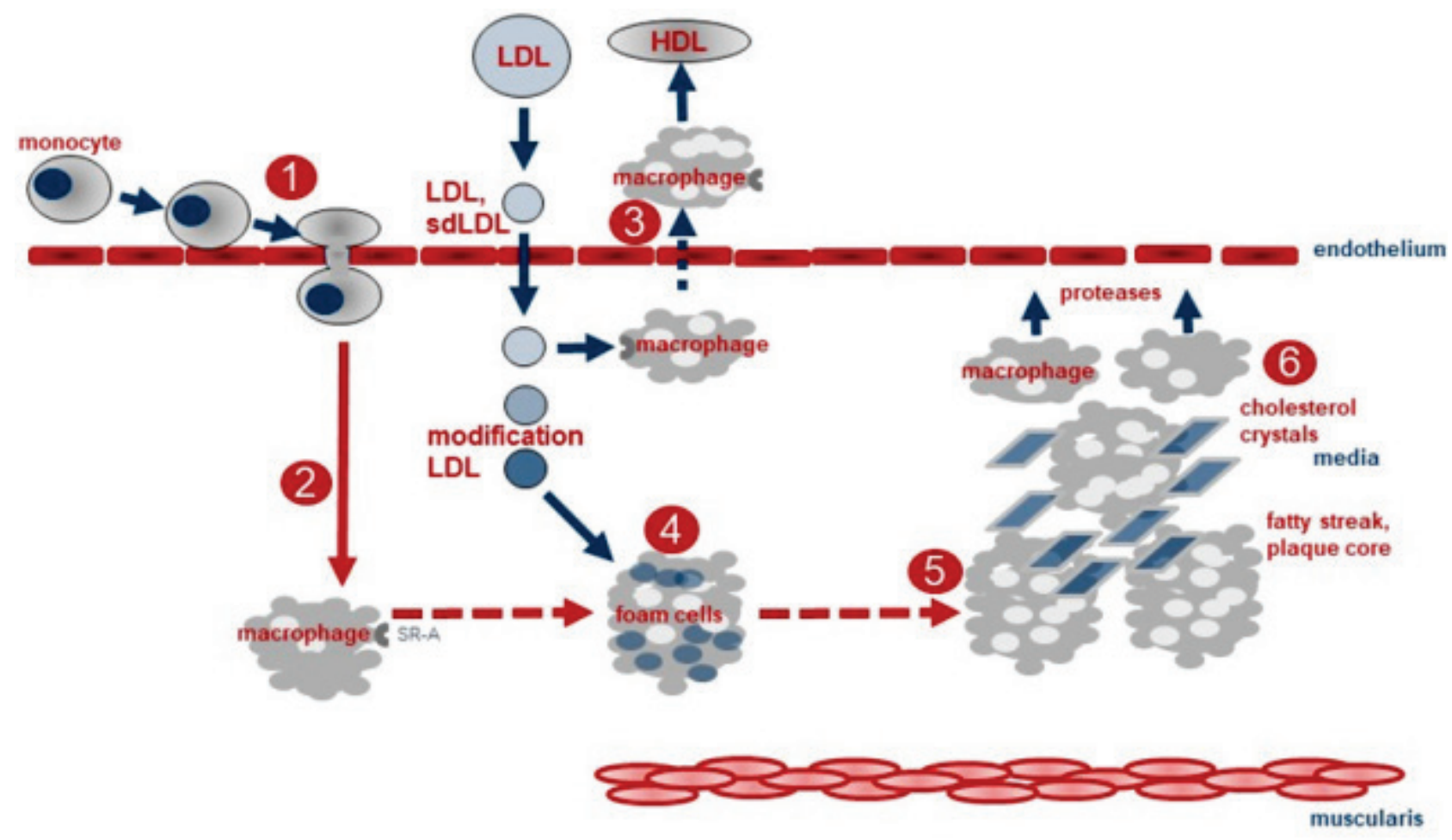

Fig. 2a. Early and late stages of atherogenesis. If the modification (oxidation, glycosylation, or nitrosylation) of extracellular stored cholesterol occurs, macrophages do not exit the subendothelial layer. Macrophages filled with lipids are then transformed into foam cells, fatty streaks develop, and the core of the atherosclerotic plaque is established. At later stages, the macrophage layer infiltrates the already developed lipid core of the plaque. The released proteases disrupt the layer and begin to destabilize the plaque.

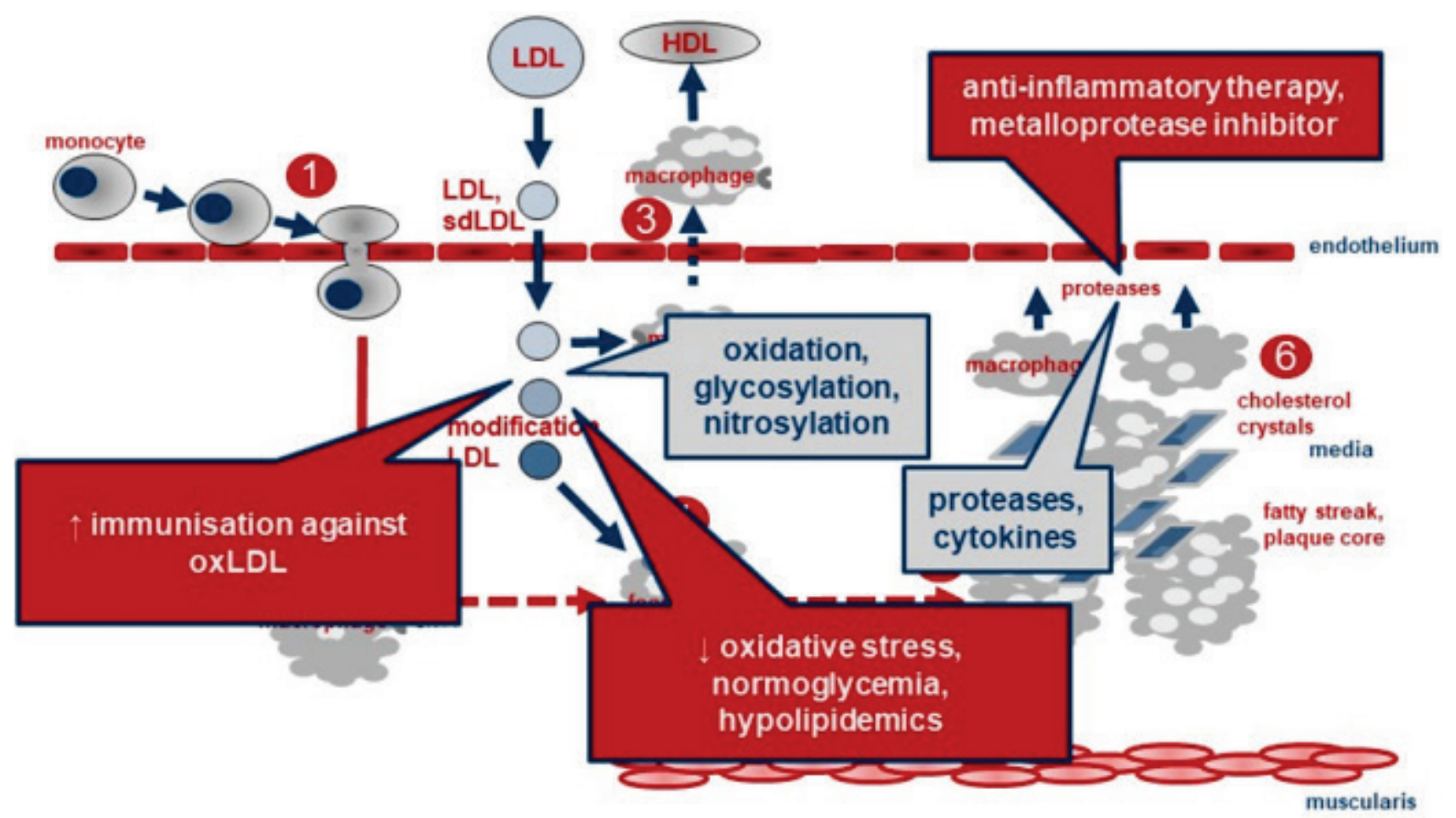

Fig. 2b. Potential for therapeutic interventions aimed at preventing the core of the atherosclerotic plaque from developing. A key aspect of the plaque development is the modification of the atherogenic lipids, the key to its destabilization and subsequent infiltration by macrophages into the subendothelial layer. The feasibility of lipid modification prevention, i.e. reducing infiltration by anti-inflammatory therapy, or the inhibition of elastase and collagenase by specific inhibitors is being investigated. 


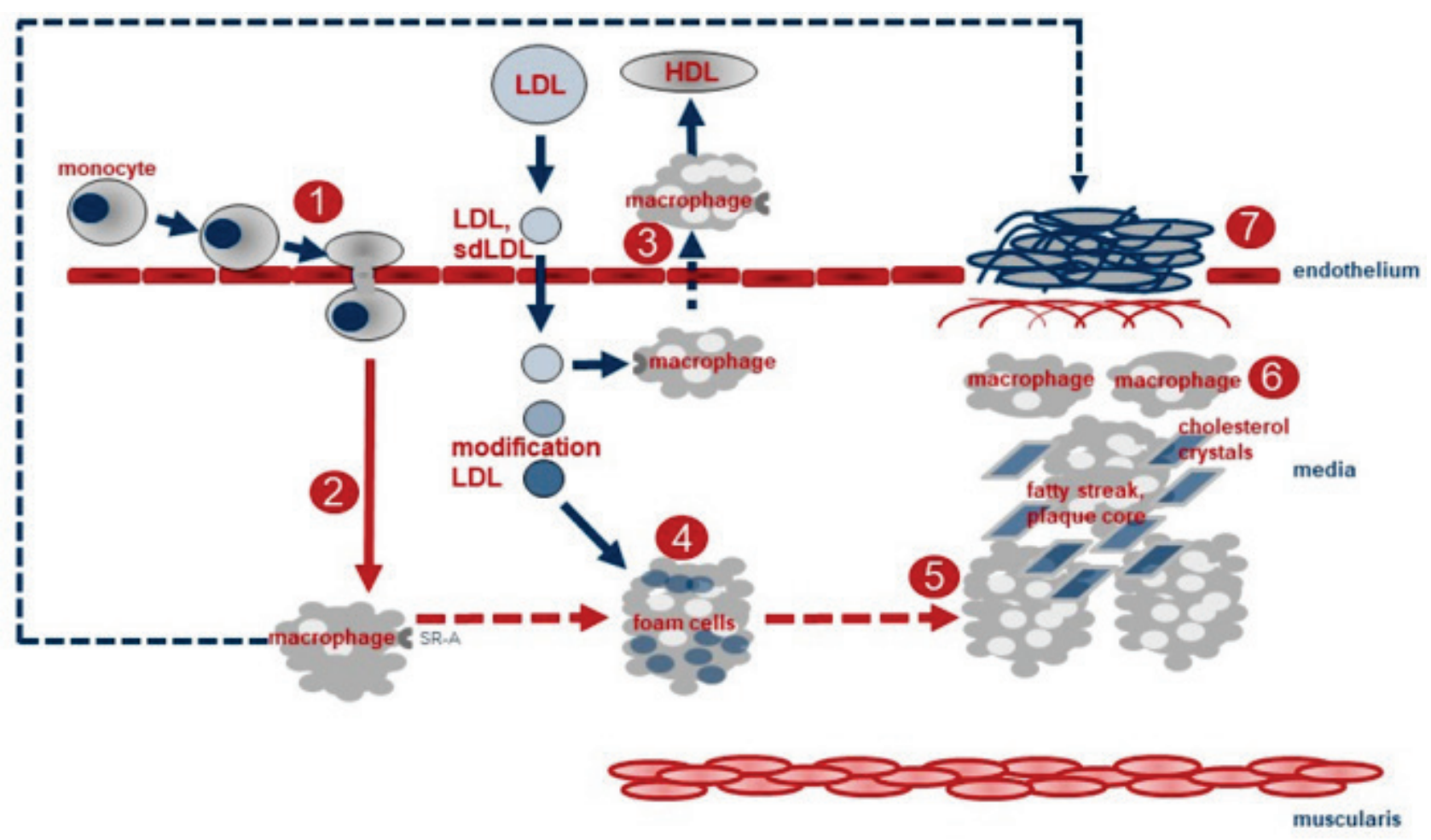

Fig. 3a. Plaque destabilization and activation of primary and secondary hemostasis. The exposure of collagen fibers after the surface of the plaque layer has been compromised, results in the release of a series of thrombocyte activating factors. Many of them are products of the inflammatory cascade.

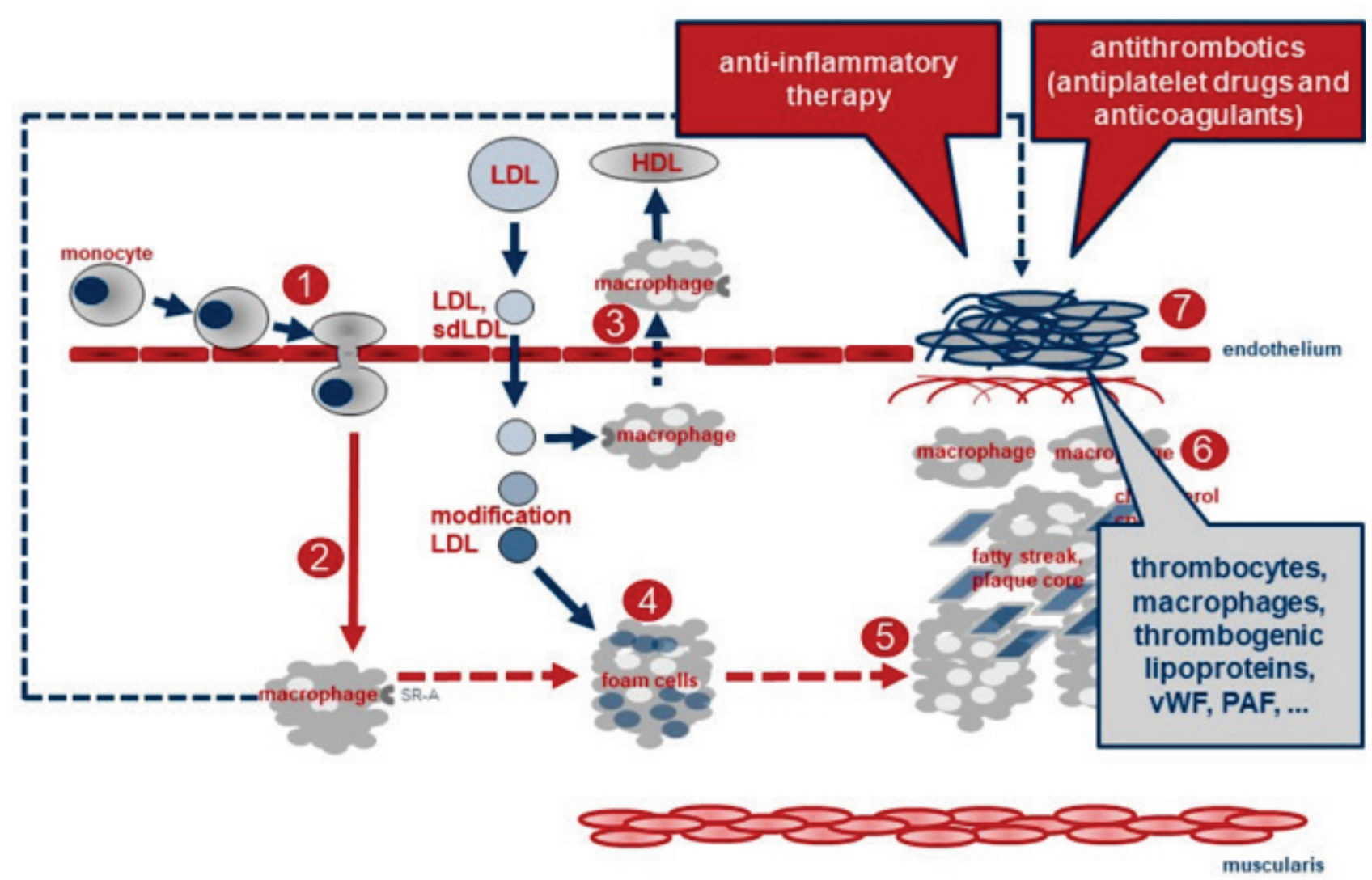

Fig. 3b. Potential for managing the development of atherothrombotic complications. In addition to already established antithrombotic therapy, the effect of anti-inflammatory therapy is also being examined. 
The cells participating in inflammatoryreparation processes, and the cytokines they produce, interfere not only with atherogenesis but also lead to thrombotic complications associated with atherosclerosis (Fig. 3a). Macrophages not only produce metalloproteases that damage the plaque layer and increase the risk of destabilization but also release thrombocyte activating factors, especially macrophage platelet-activating factor (PAF) (Estevez and Du 2017). Reciprocally, blood platelets activate a series of leukocyte mechanisms. The connection among different inflammatory-repair processes is logical if we consider the phylogenetically narrow linkage of hemostasis with the process restoring the integrity of vessel walls. When there is vascular damage, it is necessary to stop the acute bleeding (hemostasis) and subsequently repair the damaged vascular wall (inflammatory-reparative procedures).

Besides the administration of anti-thrombotics (i.e. antiplatelet treatment and anticoagulants), we can also reduce thrombogenic emergencies by interfering with the underlying risk factors of atherogenesis. Specifically, by reducing the associated thrombogenic lipoproteins, especially Lp (a), reducing the exposure to cigarette smoke, preventing and treating diabetes (Fig. 3b), and last but not least, there is growing evidence of the importance of inhibiting the primary reparative procedure, known as the inflammatory cascade, i.e. suppression of the inflammation caused by NLRP3 and the subsequent production of inflammatory and thrombogenic acute-phase molecules (particularly C-reactive protein (CRP), fibrinogen, and plasminogen activator inhibitor 1 (PAI-1).

Since the specific anti-inflammatory treatment is targeted exclusively at the inflammation cascade with the goal of reducing atherothrombotic events, the importance of the NLRP3 inflammasome in atherogenesis and thrombogenesis is advantageous at least in general (Fig. 4). The first step is to activate the cascade. This is triggered by a variety of stimuli: solid particles (e.g. cholesterol or uric acid crystals), bacterial and viral toxins or other structures, atherogenic lipoproteins (especially apoB containing), endogenous cytokines (e.g. TNF $\alpha$ ), regulatory molecules (e.g. tissue damage stimuli (especially hypoxia or temperature fluctuations). The inflammatory response (activation of NLRP3 inflammasome) has triggered several trials. Tumors involved in the immune response (leukocytes, endothelium, immunocytes, etc.) release interleukins (especially interleukin $1 \beta \quad$ (IL-1 $\beta$ ), interferons, transcription factors and other regulatory proteins that affect macrophage differentiation (polarization on macrophages of different types) thus enabling the elimination of foreign matter from tissues and facilitating further repair (Cejkova et al. 2017, Parisi et al. 2018). Similarly, the regulatory proteins activate the secretion of acute phase defense molecules (CRP, fibrinogen, or, e.g. PAI-1). These effector molecules subsequently activate a number of transcription factors (especially nuclear factor (NFאB) and thus stimulate defense and repair processes. The caspase cascade is also stimulated in parallel to eliminate damaged cells or tissues. The result is a comprehensive defense and recovery process that allows the organism to survive.

The key molecule of the acute phase, which mediates the large part of the effect, is C-reactive protein (CRP). Hepatic secretion of this reactant is stimulated by interleukin 6 (IL-6, which in a previous step was released by interleukin $1 \beta$ ). The C-reactive protein binds to the carbohydrate antigen of the bacteria and activates phagocytosis. It is this carbohydrate bond that gives the $\mathrm{C}$-reactive protein its name. Binding to the complex carbohydrates in vascular walls is not critical. The dominant structure that CRP binds to is lysophosphatidylcholine on the surface of damaged cells (and bacteria), followed by complement activation, which triggers their phagocytosis. In atherogenesis, activation of macrophages is the primary event. Elevated CRP values are associated with chronic and acute vascular events, diabetes mellitus, and hypertension. For example, higher CRPs were found in about one-half of patients after myocardial infarction, who had no evidence of another inflammatory disease (Munkhaugen et al. 2018). It must be emphasized that CRP is not a regulatory protein, but a reactant in the activation of phagocytosis and other defense responses. As will be discussed later, due to the proatherogenic effect of this protein, the idea is that the reduction in CRP will reduce the incidence of atherothrombotic events. Originally, CRP was perceived as a risk marker, however, now the concept has changed, and it turns out to be an active player. 


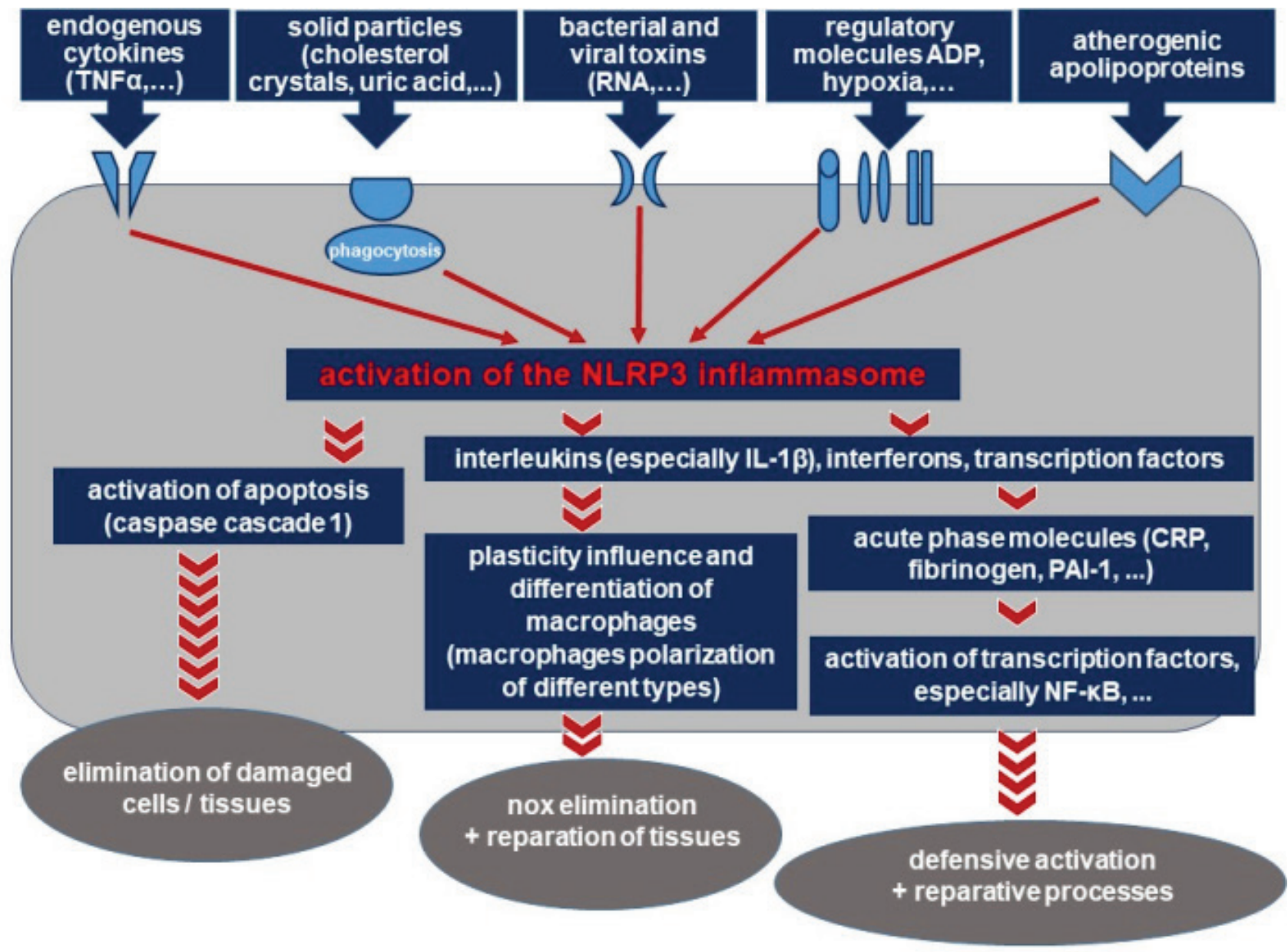

Fig. 4. The importance of the inflammatory-reparation cascade associated with the NLRP3 inflammasome. Several humoral stimuli, corpuscles, etc., activate the phylogenetically old inflammatory response of NLRP3. On the one hand, the activation of interleukins, interferons and other factors is now at the forefront, with the goal of modulation of macrophage function with the elimination of NOx or the release of effector-like molecules during acute-phase activation of the reparation and defense processes. Removal of damaged cells is ensured by triggering the caspase cascade. Activation of the NLRP3 inflammasome plays an important role in atherogenesis, plaque destabilization, and eventual thrombosis.

\section{Does the activation of the inflammatory cascade have a direct impact on the occurrence of atherothrombotic events?}

For NLRP3 inflammasome, as with any complex system, its activation may not always be beneficial. This is the case with atherogenesis and atherothrombosis, and at the pathogenesis level, relationships have been described. However, the question of the clinical significance of inflammation in the atherosclerosis/ atherothrombosis relationship remains open.

The significance of chronic inflammation atherogenesis acceleration can be well documented on the example of periodontitis. This chronic inflammation appears to be unrelated to cardiovascular and cerebrovascular events. However, many studies have found a close correlation between periodontal index or tooth loss and the number of atherothrombotic events. Similarly, two studies found that the presence of periodontitis increases the risk of vascular events more than twice (Beukers et al. 2017, Im et al. 2018). The probable relationship of periodontitis and atherogenesis involves local activation of the inflammatory cascade (at the gum level) and its systemic activation (by bacteria) with the release of cytokines (TNF $\alpha$, IL-6, and IL-1 $\beta$ ) and the acute-phase molecules (CRP, fibrinogen, PAI-1, and amyloid AND). Similarly, the link between other chronic inflammations, e.g. psoriasis or rheumatoid arthritis and atherogenesis, is also documented. These chronic inflammatory diseases also show a higher concentration of acute-phase molecules such as CRP and fibrinogen. Even in these cases, there is a correlation between their levels and atherogenesis (Alpsoy et al. 2014, Siegel et al. 2013). Importantly, there are more examples linking 
chronic inflammation with atherogenesis.

Another example of such a relationship is acute inflammation linked to thrombotic complications; during viral infections an increase in atherothrombotic events, e.g. myocardial infarctions, have been seen to increase (Kwong et al. 2018). Acute viral disease increases the risk of coronary events by about six times. The number of events increased from $0.97 /$ week to $5.5 /$ week for every 100 patients (compare the number of strokes the week before and the week after the infection). The highest increase was observed with the influenza $B$ virus infection. There was no accelerated atherogenesis, but the activation of thrombosis and probably the instability of plaque was increased by the macrophage activity.

The third area where chronic inflammation is unfavorable involves arrhythmias, often malignant arrhythmias (Lazzerini et al. 2019). There is a higher incidence of sudden coronary death in patients with, e.g. rheumatoid arthritis, which contributes to about a $50 \%$ increase in coronary mortality in these patients (Lazzerini et al. 2017).

To summarize, the inflammatory-reparative process participates in both atherogenesis and thrombotic complications in several locations. In addition, it increases the risk of malignant arrhythmias. There is evidence that acute or chronic inflammation has a direct impact on the prognosis of patients. Thus, experimental data is well correlated with clinical observations.

\section{What are the pharmacological possibilities of influencing the inflammatory-reparative process in the prophylaxis of atherothrombotic events?}

We have reasons to test the effectiveness of inhibiting inflammatory processes in the prevention of atherothrombotic events. Evidence is already positive from previously established procedures to reduce the inflammatory component of atherogenesis and thrombosis through diet, lifestyle, or pharmacological interventions (e.g. smoking abstinence, hypolipidemic or antithrombotic treatment, or treatment of diabetes). However, we do not know the effects of a treatment strategy that directly targets inflammatory cytokines (especially interleukins and $\mathrm{TNF} \alpha$ ) that results in a reduction in acute phase molecules, particularly inflammatory activator CRP, prothrombotic fibrinogen, and fibrinolysis inhibitor PAI-1.

A variety of life-saving measures, such as weight reduction or increased fiber consumption, lead to a significant decrease in plasma CRP concentration (North et al. 2009). Similarly, hypolipidemic treatment, in particular statins, can reduce CRP concentration by almost $50 \%$ (Deanfield et al. 2010). The combination of hypolipidemics, particularly atorvastatin, ezetimibe, and bempedoic acid, can decrease CRP concentration by almost two-thirds. Similarly, antiplatelet drugs also decrease CRP concentrations. Clopidogrel treatment reduced hs-CRP by more than half (Hajsadeghi et al. 2016). Far less, if at all, it will reduce both hs-CRP and ASA concentrations administered in antiplatelet doses (Berg et al. 2013).

Other pharmacological groups can also significantly reduce CRP levels, including antileukotrienes, xanthine oxidase inhibitors, antiphlogistics, and some antidiabetic drugs (Passacquale et al. 2016). However, there is no doubt that the main effect of hypolipidemics, in the prevention of atherothrombotic events, is the reduction in LDL-cholesterol (Schmiedtova et al. 2014). However, it is conceivable that a decrease in CRP may also be beneficial for its prognostic value. The role of decreased homocysteine levels is not yet fully understood (Karolczak et al. 2018).

\section{The CANTOS study, the first evidence of the efficacy of anti-inflammatory therapy in the secondary prevention of atherothrombotic events}

As documented in the previous review, there is good evidence for the hypothesis that inflammatoryreparative processes are involved in atherogenesis and thrombogenesis. The next logical step was to determine if an intervention aimed at reducing inflammation activity would lead to a slowing of atherogenesis, and a reduction in atherothrombotic complications. The inhibition of the inflammatory-reparatory processes can be performed in several ways, many of which are examined in Table 1. However, the CANTOS study (Canakinumab AntiInflammatory Thrombosis Outcomes Study), has already shown that the "anti-inflammatory" strategy is effective and safe. This opens up the possibility of further therapeutic interventions. 
Table 1. Overview of drugs with anti-inflammatory effect with potential use in the treatment of atherothrombotic diseases (including studies verifying their effect).

\begin{tabular}{|c|c|c|c|}
\hline Drug & Mechanism of action & Effect in the experiment & Clinical effect \\
\hline $\begin{array}{l}\text { Mab anti-IL-1 } \beta \\
\text { (canakinumab) }\end{array}$ & $\begin{array}{l}\text { IL-1 } \beta \text { blockade } \\
\text { (inhibition of } \\
\text { inflammation and } \\
\text { reparation) }\end{array}$ & $\begin{array}{l}\text { secretion decrease IL-1 } \beta \text {, } \\
\text { IL-6, and CRP }\end{array}$ & $\begin{array}{l}\text { documented a positive effect on } \\
\text { a decrease of MACE (major } \\
\text { adverse cardiac events) in the } \\
\text { study CANTOS }\end{array}$ \\
\hline $\begin{array}{l}\text { Mab anti-TNF } \alpha- \\
\text { inhibitors TNF } \alpha \\
\text { (etanercept, infliximab, } \\
\text { adalimumab) }\end{array}$ & $\begin{array}{l}\text { TNF } \alpha \text { blockade } \\
\text { (inhibition of } \\
\text { inflammation and } \\
\text { reparation) }\end{array}$ & $\begin{array}{l}\text { decrease secretion IL-6 } \\
\text { and CRP }\end{array}$ & $\begin{array}{l}\text { documented decrease in } \mathrm{CV} \\
\text { events in patients with } \\
\text { rheumatoid arthritis in the } \\
\text { CORRONA study for etanercept } \\
\text { (other studies in psoriasis are } \\
\text { ongoing) }\end{array}$ \\
\hline $\begin{array}{l}\text { antimytotika } \\
\text { (colchicine) }\end{array}$ & $\begin{array}{l}\text { inhibition of mitosis, } \\
\text { inhibition of leukocyte } \\
\text { proliferation }\end{array}$ & $\begin{array}{l}\text { secretion decrease IL-1 } \beta \text {, } \\
\text { stabilization of } \\
\text { macrophages }\end{array}$ & $\begin{array}{l}\text { a possible decrease in MI and } \\
\text { non-embolic stroke; COLCOT } \\
\text { study is ongoing }\end{array}$ \\
\hline $\begin{array}{l}\text { Mab against receptors } \\
\text { IL-6 (tocilizumab) }\end{array}$ & $\begin{array}{l}\text { blockade of binding of } \\
\text { IL- } 6 \text { to the receptor } \\
\text { (inhibition of } \\
\text { inflammation and } \\
\text { reparation) }\end{array}$ & $\begin{array}{l}\text { CRP decrease, endothelial } \\
\text { dysfunction treatment }\end{array}$ & $\begin{array}{l}\text { documented decrease of MACE } \\
\text { in patients with rheumatoid } \\
\text { arthritis vs. adalimumab in the } \\
\text { MEASURE study; a comparable } \\
\text { effect to etanercept in the } \\
\text { ENTRACTE study }\end{array}$ \\
\hline $\begin{array}{l}\text { immunosuppressive } \\
\text { (metotrexat) }\end{array}$ & immunosuppression & $\begin{array}{l}\text { blockade of DNA } \\
\text { synthesis, no CRP or } \\
\text { interleukins influence }\end{array}$ & $\begin{array}{l}\text { assessed decrease of MI and CV } \\
\text { mortality in patients with RA or } \\
\text { psoriasis; the CIRT trial showed } \\
\text { that low-dose methotrexate does } \\
\text { not reduce IL-1 } \beta \text {, IL- } 6 \text {, hs-CRP, } \\
\text { or CV events }\end{array}$ \\
\hline $\begin{array}{l}\text { Mab anti-IL-12 } \\
\text { (ustekinumab) }\end{array}$ & $\begin{array}{l}\text { IL- } 12 \text { and IL- } 23 \\
\text { blockade (inhibition of } \\
\text { inflammation and } \\
\text { reparation) }\end{array}$ & $\begin{array}{l}\text { decreased NK- and T-cells } \\
\text { activations; decrease CRP }\end{array}$ & $\begin{array}{l}\text { documented decrease of } \\
\text { inflammation in vessels in } \\
\text { psoriatic patients; the VIP-U } \\
\text { study in psoriasis is ongoing }\end{array}$ \\
\hline statins & $\begin{array}{l}\text { inhibition of sterol core } \\
\text { synthesis }\end{array}$ & $\begin{array}{l}\text { possible lipidic and extra- } \\
\text { lipidic effects }\end{array}$ & $\begin{array}{l}\text { documented decrease of CV } \\
\text { mortality and morbidity (many } \\
\text { studies, for example, } 4 \mathrm{~S} \text { study) }\end{array}$ \\
\hline $\begin{array}{l}\text { inhibitors of } \\
\text { phosphodiesterase } 3 \\
\text { (PDE-3) } \\
\text { (cilostazol) }\end{array}$ & $\begin{array}{l}\text { inhibition of } \\
\text { proliferation in vessels } \\
\text { walls }\end{array}$ & $\begin{array}{l}\text { decrease in subendothelial } \\
\text { infiltration by macrophage, } \\
\text { and decrease proliferation } \\
\text { of smooth muscle cells in } \\
\text { plaque }\end{array}$ & $\begin{array}{l}\text { possible decreased } \\
\text { atherosclerotic plaque, } \\
\text { protection against restenosis in } \\
\text { small trials }\end{array}$ \\
\hline \multirow[t]{2}{*}{$\begin{array}{l}\text { non-steroidal } \\
\text { antirheumatic }\end{array}$} & COX 1 blockade & $\begin{array}{l}\text { especially antithrombotic } \\
\text { effect }\end{array}$ & $\begin{array}{l}\text { decreased CV } \\
\text { mortality/morbidity after ASA }\end{array}$ \\
\hline & COX 2 blockade & decrease in IL-6 and CRP & $\begin{array}{l}\text { paradoxical increase in } \mathrm{CV} \\
\text { events after some coxibs }\end{array}$ \\
\hline
\end{tabular}

According to Yu et al. (2017), updated based on studies Greenberg et al. (2011), Kim et al. (2017), Bacchiega et al. (2017). IL - interleukin, CRP - C-reactive protein, TNF - tumor necrosis factor, mAb - monoclonal antibody, CVD - cardiovascular, MI - myocardial infarction, CVA - stroke, RA - rheumatoid arthritis, COX - cyclooxygenase, ASA - acetylsalicylic acid. 


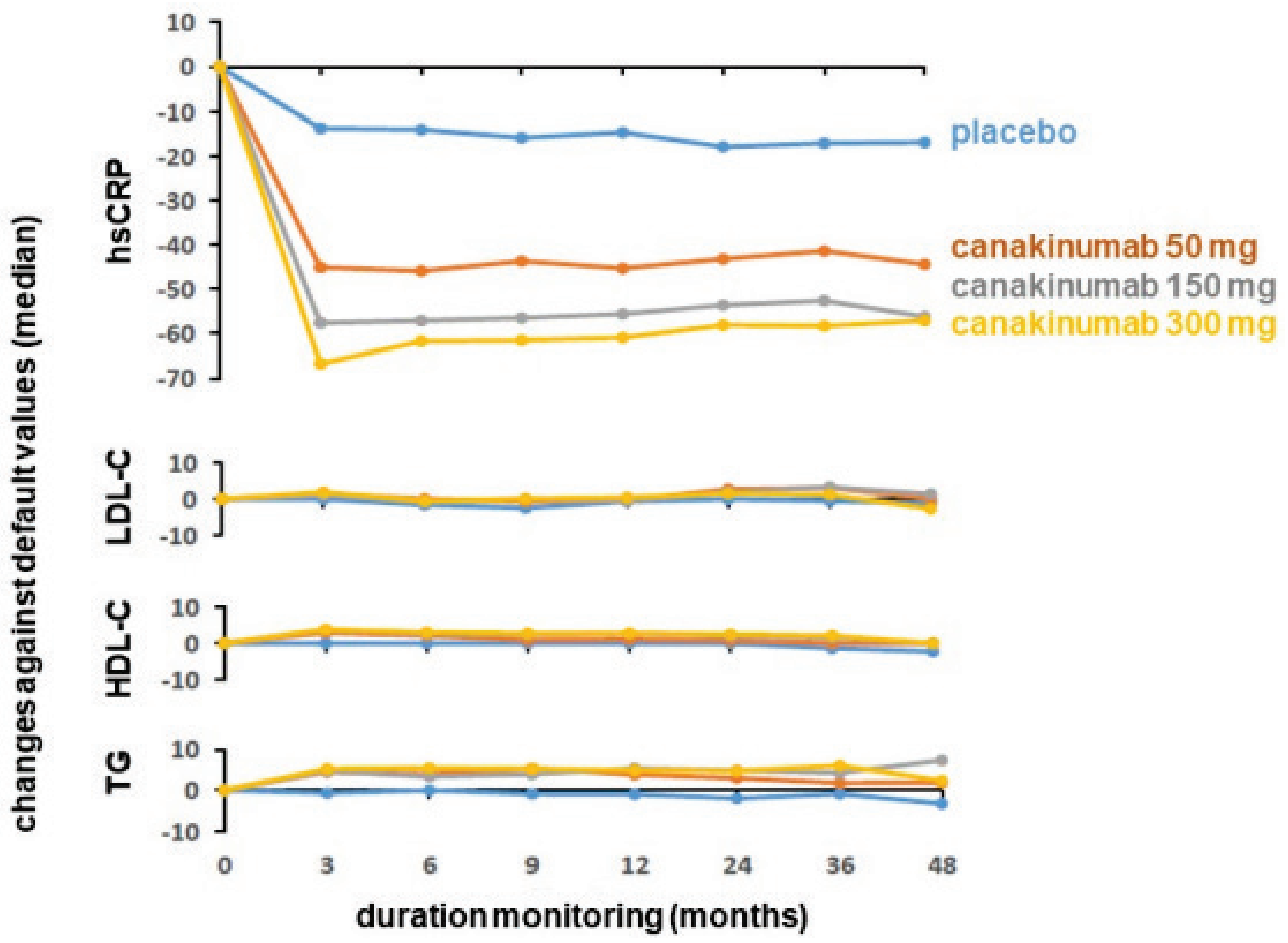

Fig. 5. Significant decrease in hs-CRP concentration and minimal change in lipid concentration during treatment with different doses of canakinumab used in the CANTOS study. According to (Ridker et al. 2017a).

The authors of the CANTOS questioned whether stabilized patients after myocardial infarction with optimal LDL-cholesterol but with a high levels of C-reactive protein (measured hs-CRP) would need anti-inflammatory treatment to reduce the residual cardiovascular risk (Ridker et al. 2017a). CANTOS included more than 10,000 patients, treated with three different doses of canakinumab and a placebo. The LDL-cholesterol intake was close to optimal (on average, $2.1 \mathrm{mmol} / \mathrm{l}$ ); on the other hand, hs-CRP was higher (on average, $4.1 \mathrm{mg} / \mathrm{l}$ ).

Canakinumab, as suggested by the "-umab" ending, is a fully human monoclonal antibody against interleukin $1 \beta$ (IL-1 $\beta$ ). Binding completely neutralizes IL-1 $\beta$ activity. Interleukin $1 \beta$ (part of the complex of proinflammatory proteins of NLRP3 inflammasome) stands at the top of the cascade that triggers the defense and repair processes known as inflammation. The direct result of low IL-1 $\beta$ activity is a decrease in the number of inflammatory cytokines, particularly interleukin-6 (IL-6) and CRP, resulting in an attenuation of the entire defense process. On the one hand, it reduces the defenses of the organism, e.g. against infection, while on the other hand, it inhibits the chronic processes where inflammation is more important. An example is rheumatic and metabolic arthritis or atherogenesis where inflammation interactions with cholesterol crystals play an important role throughout the process.

The elimination half-life of canakinumab in plasma is long (4-8 weeks); therefore, it is administered subcutaneously and lasts 3 months. The use of canakinumab is approved in several indications for inflammatory neurological or articular diseases (e.g. gout). However, the wider application is still limited by its very high cost.

During three to four years of monitoring (mean, 3.7 years), a significant decrease in hs-CRP concentration (CRP determined using a highly sensitive method) was observed, and after adjustment for the placebo effect, the level was decreased by almost $40 \%$. Similarly, IL-6 concentrations were also decreased. In contrast, the lipidogram did not change during the study 
(Fig. 5). The primary indicator MACE (cardiovascular mortality, myocardial infarction, and stroke) was significantly reduced by $15 \%$, RR 0.85 (0.74-0.98), $\mathrm{p}=0.02$ with the higher dose of canakinumab (Fig. 6). In absolute figures, the primary indicator (MACE) was $4.5 \%$ per year for higher doses of canakinumab and $3.9 \%$ per year for the placebo. The absolute benefit was not massive and major CVD events only decreased by $0.6 \%$ per year. The treatment with canakinumab did not affect cardiovascular mortality; however, with the relative shortness of the study, a positive effect on this most serious indicator should not be expected.

When monitoring safety, there was no difference between active treatment or placebo in the incidence of all serious adverse events. Statistically, however, the incidence of deaths from infections (about $0.1 \%$ in absolute terms) increased (by about $70 \%$ ). On the contrary, and surprisingly, was the fall in cancer deaths by half, i.e. RR 0.49 (0.31-0.75), p=0.0009, in absolute terms by $0.3 \%$ per year (Ridker et al. 2017b). In the analysis of carcinoma types, the incidence of bronchogenic carcinoma, in particular, decreased by three quarters: RR 0.23 (0.10-0.54), $\mathrm{p}=0.0002$, respectively, by $0.2 \%$ per year. However, the decline in tumor mortality was more than offset by the increase in infection mortality.

\section{$0.85(0.74-0.98), p=0.02 \quad 0.76(0.62-0.92), p<0.05 \quad 0.68(0.58-0.81), p<0.001$}

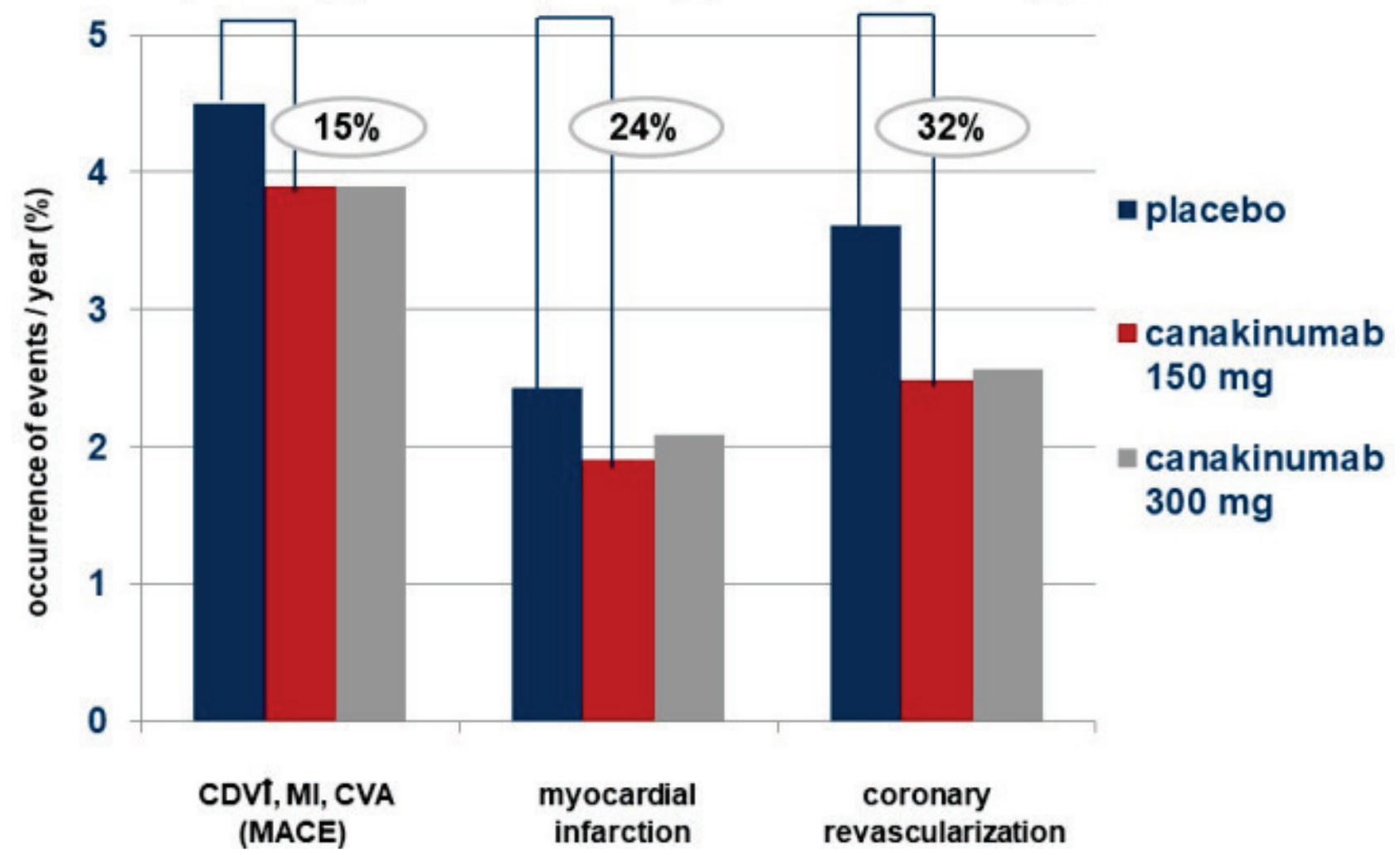

Fig. 6. Decreased incidence of major coronary events using medium to higher doses of canakinumab in the CANTOS study. According to Ridker et al. (2017a).

To summarize the outcome of the study, from a clinical point of view, the benefit was not great. The decline in MACE by a relative $15 \%$, more precisely an absolute $0.6 \%$, was mainly due to a decrease incidence of myocardial infarction, mortality was not affected. Considering the current price of canakinumab, which is around 200,000 USD/year, it is not possible at this time to talk about pharmacoeconomic effectiveness. On the other hand, the study is highly valued for the new concept in the treatment of atherothrombotic disorders. Despite the "anti-inflammatory" effect of hypolipidemics (especially statins), this is the first prognostic controlled trial that has shown that treatment targeted at inflammatory cytokines may be beneficial. Specifically, a decreased incidence of atherothrombotic events (especially coronary) in patients after myocardial infarction by direct blockade of proinflammatory IL-1 $\beta$ without affecting the lipidogram was documented. In 
addition, there was a significant bonus in the form of a decrease in cancer incidence and mortality. A decrease in isolated mortality to different types of cancer tripled the single significant risk of treatment, i.e. there was higher mortality from infectious diseases. Even though the absolute values only increased by one percent, the increase was statistically significant.

Looking at the study from a wider perspective, a new treatment strategy for atherothrombotic disease is developing. However, in order to get optimal treatment, it will be necessary to wait for the outcome of a similar larger study, COLCOT, which is examining the effect of small doses of the antimycotic colchicine for secondary prevention of atherothrombotic events. The results are expected in 2020. The pilot study has produced some promising results, i.e. evidence of a decrease in the incidence of major vascular events by more than one third (Nidorf et al. 2013). Another trial, CIRT (Cardiovascular Inflammation Reduction Trial), showed that low-dose methotrexate does not reduce IL-1 $\beta$, IL-6, hs-CRP, or CV events compared with placebo among patients with established coronary artery disease and either diabetes mellitus or metabolic syndrome (Ridker et al. 2019).

In addition to treating dyslipidemia, hypertension, diabetes, smoking abstinence, metabolic syndrome, antithrombotic treatment, or suppression of hyperactivated regulatory mechanisms, etc., a new option, anti-inflammatory therapy, is being used to treat atherothrombosis. The complex disease of atherothrombosis will be treated in a truly comprehensive fashion. In conclusion, it is very difficult to "improve nature", but we may be able to succeed when it comes to the prophylaxis of atherothrombotic events.

\section{Conflict of Interest}

There is no conflict of interest.

\section{Acknowledgements}

Grant support: PROGRESS Q 38.

\section{References}

ALLAM AH, MANDOUR ALI MA, WANN LS, THOMPSON RC, SUTHERLAND ML, SUTHERLAND JD, FROHLICH B, MICHALIK DE, ZINK A, LOMBARDI GP, WATSON L, COX SL, FINCH CE, MIYAMOTO MI, SALLAM SL, NARULA J, THOMAS GS: Atherosclerosis in ancient and modern Egyptians: the Horus study. Glob Heart 9: 197-202, 2014.

ALPSOY S, AKYUZ A, ERFAN G, AKKOYUN DC, TOPCU B, GUZEL S, KAYA S, KULAC M: Atherosclerosis, some serum inflammatory markers in psoriasis. G Ital Dermatol Venereol 149: 167-175, 2014.

BACCHIEGA BC, BACCHIEGA AB, USNAYO MJ, BEDIRIAN R, SINGH G, PINHEIRO GD: Interleukin 6 inhibition and coronary artery disease in a high-risk population: a prospective community-based clinical study. $J$ Am Heart Assoc 6: e005038, 2017.

BERG K, LANGAAS M, ERICSSON M, PLEYM H, BASU S, NORDRUM IS, VITALE N, HAAVERSTAD R: Acetylsalicylic acid treatment until surgery reduces oxidative stress and inflammation in patients undergoing coronary artery bypass grafting. Eur J Cardiothorac Surg 43: 1154-1163, 2013.

BEUKERS NG, VAN DER HEIJDEN GJ, VAN WIJK AJ, LOOS BG: Periodontitis is an independent risk indicator for atherosclerotic cardiovascular diseases among 60174 participants in a large dental school in the Netherlands. J Epidemiol Community Health 71: 37-42, 2017.

CEJKOVA S, KRALOVA L, I, FRONEK J, JANOUSEK L, KRALOVA A, ZDYCHOVA J, POLEDNE R: Pro-inflammatory gene expression in adipose tissue of patients with atherosclerosis. Physiol Res 66: 633-640, 2017.

DEANFIELD JE, SELLIER P, THAULOW E, BULTAS J, YUNIS C, SHI H, BUCH J, BECKERMAN B: Potent antiischaemic effects of statins in chronic stable angina: incremental benefit beyond lipid lowering? Eur Heart $J$ 31: 2650-2659, 2010.

ESTEVEZ B, DU X: New concepts and mechanisms of platelet activation signaling. Physiology (Bethesda) 32: 162-177, 2017.

EVERETT BM, PRADHAN AD, SOLOMON DH, PAYNTER N, MACFADYEN J, ZAHARRIS E, GUPTA M, CLEARFIELD M, LIBBY P, HASAN AA, GLYNN RJ, RIDKER PM: Rationale and design of the Cardiovascular Inflammation Reduction Trial: a test of the inflammatory hypothesis of atherothrombosis. Am Heart J 166: 199-207, 2013. 
GREENBERG JD, KREMER JM, CURTIS JR, HOCHBERG MC, REED G, TSAO P, FARKOUH ME, NASIR A, SETOGUCHI S, SOLOMON DH: Tumour necrosis factor antagonist use and associated risk reduction of cardiovascular events among patients with rheumatoid arthritis. Ann Rheum Dis 70: 576-582, 2011.

HAJSADEGHI S, CHITSAZAN M, CHITSAZAN M, SALEHI N, AMIN A, MALEKI M, BABAALI N, ABDI S, MOHSENIAN M: Changes of high sensitivity c-reactive protein during clopidogrel therapy in patients undergoing percutaneous coronary intervention. Res Cardiovasc Med 5: e28997, 2016.

IM SI, HEO J, KIM BJ, CHO KI, KIM HS, HEO JH, HWANG JY: Impact of periodontitis as representative of chronic inflammation on long-term clinical outcomes in patients with atrial fibrillation. Open Heart 5: e000708, 2018.

KAROLCZAK K, KUBALCZYK P, GLOWACKI R, PIETRUSZYNSKI R, WATALA C: Aldosterone modulates blood homocysteine and cholesterol in coronary artery disease patients - a possible impact on atherothrombosis? Physiol Res 67: 197-207, 2018.

KIM SC, SOLOMON DH, ROGERS JR, GALE S, KLEARMAN M, SARSOUR K, SCHNEEWEISS S: Cardiovascular safety of tocilizumab versus tumor necrosis factor inhibitors in patients with rheumatoid arthritis: a multi-database cohort study. Arthritis Rheumatol 69: 1154-1164, 2017.

KIMURA T, TSE K, SETTE A, LEY K: Vaccination to modulate atherosclerosis. Autoimmunity 48: 152-160, 2015.

KWONG JC, SCHWARTZ KL, CAMPITELLI MA, CHUNG H, CROWCROFT NS, KARNAUCHOW T, KATZ K, KO DT, MCGEER AJ, MCNALLY D, RICHARDSON DC, ROSELlA LC, SIMOR A, SMIEJA M, ZAHARIADIS G, GUBBAY JB: Acute myocardial infarction after laboratory-confirmed influenza infection. NEngl J Med 378: 345-353, 2018.

LAZZERINI PE, CAPECCHI PL, LAGHI-PASINI F: Systemic inflammation and arrhythmic risk: lessons from rheumatoid arthritis. Eur Heart J 38: 1717-1727, 2017.

LAZZERINI PE, LAGHI PASINI F, ACAMPA M, CAPECCHI PL: Inflammatory cytokines, life-threatening arrhythmias and premature mortality in chronic inflammatory arthritis: time to focus on. Ann Rheum Dis $\mathbf{7 8}$ : e98, 2019.

MUNKHAUGEN J, OTTERSTAD JE, DAMMEN T, GJERTSEN E, MOUM T, HUSEBYE E, GULLESTAD L: The prevalence and predictors of elevated C-reactive protein after a coronary heart disease event. Eur J Prev Cardiol 25: 923-931, 2018.

NIDORF SM, EIKELBOOM JW, BUDGEON CA, THOMPSON PL: Low-dose colchicine for secondary prevention of cardiovascular disease. J Am Coll Cardiol 61: 404-410, 2013.

NORTH CJ, VENTER CS, JERLING JC: The effects of dietary fibre on C-reactive protein, an inflammation marker predicting cardiovascular disease. Eur J Clin Nutr 63: 921-933, 2009.

PARISI L, GINI E, BACI D, TREMOLATI M, FANULI M, BASSANI B, FARRONATO G, BRUNO A, MORTARA L: Macrophage polarization in chronic inflammatory diseases: killers or builders? J Immunol Res 2018 : 8917804, 2018.

PASSACQUALE G, DI GP, FERRO A: The role of inflammatory biomarkers in developing targeted cardiovascular therapies: lessons from the cardiovascular inflammation reduction trials. Cardiovasc Res 109: 9-23, 2016.

RIDKER PM, EVERETT BM, THUREN T, MACFADYEN JG, CHANG WH, BALLANTYNE C, FONSECA F, NICOLAU J, KOENIG W, ANKER SD, KASTELEIN JJP, CORNEL JH, PAIS P, PELLA D, GENEST J, CIFKOVA R, LORENZATTI A, FORSTER T, KOBALAVA Z, VIDA-SIMITI L, FLATHER M, SHIMOKAWA H, OGAWA H, DELLBORG M, ROSSI PRF, TROQUAY RPT, LIBBY P, GLYNN RJ: Antiinflammatory therapy with canakinumab for atherosclerotic disease. $N$ Engl J Med 377: 1119-1131, $2017 \mathrm{a}$.

RIDKER PM, MACFADYEN JG, THUREN T, EVERETT BM, LIBBY P, GLYNN RJ: Effect of interleukin-1beta inhibition with canakinumab on incident lung cancer in patients with atherosclerosis: exploratory results from a randomised, double-blind, placebo-controlled trial. Lancet 390: 1833-1842, 2017b.

RIDKER PM, EVERETT BM, PRADHAN A, MACFADYEN JG, SOLOMON DH, ZAHARRIS E, MAM V, HASAN A, ROSENBERG Y, ITURRIAGA E, GUPTA M, ET AL.: Low-dose methotrexate for the prevention of atherosclerotic events. $N$ Engl J Med 380: 752-762, 2019.

SCHMIEDTOVA M, HECZKOVA M, KOVAR J, KRALOVA LESNA I, POLEDNE R: Reverse transport of cholesterol is the reason for resistance to development of atherosclerosis in Prague Hereditary Hypercholesterolemic (PHHC) rat. Physiol Res 63: 591-596, 2014. 
SIEGEL D, DEVARAJ S, MITRA A, RAYCHAUDHURI SP, RAYCHAUDHURI SK, JIALAL I: Inflammation, atherosclerosis, and psoriasis. Clin Rev Allergy Immunol 44: 194-204, 2013.

YU M, TSAI SF, KUO YM: The therapeutic potential of anti-inflammatory exerkines in the treatment of atherosclerosis. Int J Mol Sci 18: E1260, 2017. 